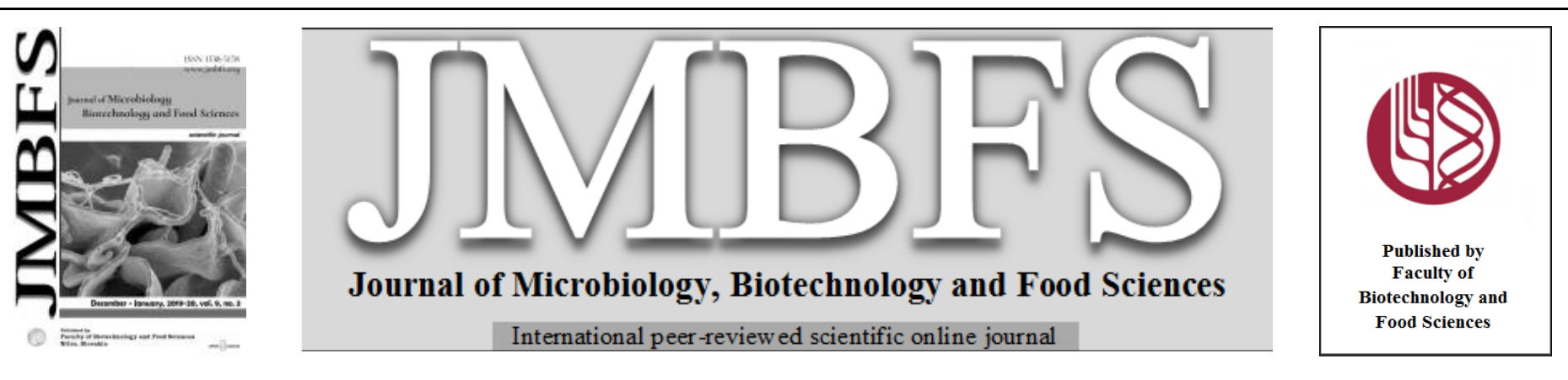

\title{
THE IMPACT OF THE FERMENTATION CONDITIONS ON THE ESTER PRODUCING CAPACITY OF DIFFERENT SACCHAROMYCES CEREVISIAE STRAINS AND THE ORGANOLEPTIC PROFILE OF CABERNET SAUVIGNON WINES
}

\author{
Tatyana Yoncheva*1, Hristo Spasov², Georgi Kostov² \\ $\operatorname{Address(es):~}$ \\ ${ }^{1}$ Institute of Viticulture and Enology, Department of Vine-Selection, Enology and Chemistry, 1 "Kala tepe" str., 5800 Pleven, Bulgaria. \\ ${ }^{2}$ University of Food Technologies, Department of Technology of Wine and Brewing, 26 "Maritsa” blvd., 4002 Plovdiv, Bulgaria.
}

*Corresponding author: $\underline{t}$ ion@abv.bg

doi: $10.15414 / j m b f s .2019 / 20.9 .3 .562-566$

ARTICLE INFO

Received 7. 3. 2019

Revised 31. 5. 2019

Accepted 5. 6. 2019

Published 1. 12. 2019

Regular article

open $O$ access

\begin{abstract}
The ester producing capacity of two strains of Saccharomyces cerevisiae was investigated, depending on the alcoholic fermentation conditions of grape pulp from Cabernet Sauvignon variety. The influence of the temperature $\left(20^{\circ} \mathrm{C}, 24^{\circ} \mathrm{C}, 28^{\circ} \mathrm{C}\right)$ and the inoculum amount of yeast culture $(2 \%, 3 \%, 4 \%)$ on the total esters synthesized during the process was monitored. Neural networks were implemented and mathematical models were derived, adequately describing the fermentation processes at the combination of grape variety - yeast strain - conditions. The results of gas chromatographic analysis identified methyl acetate, ethyl acetate, propyl acetate, isobutyl acetate, butyl acetate, isoamyl acetate, amyl acetate, ethyl hexanoate, ethyl octanoate, ethyl decanoate in the wines. It was found that the impact of esters produced by the yeasts on the organoleptic profile of the wines was not because of their total amount but mainly due to the ratio between the individual representatives. Under the experiment conditions the strain Saccharomyces cerevisiae 8-11, fermented at $28^{\circ} \mathrm{C}$, with $3 \%$ inoculum yeast culture was identified as more suitable for the production of Cabernet Sauvignon wines.
\end{abstract}

\section{INTRODUCTION}

Wine is a drink of complex chemical composition, as one of its main organoleptic characteristics being aroma. It is of a complex nature, formed by several thousand volatile components in concentrations ranging from several $\mathrm{mg} . \mathrm{dm}^{-3}$ to some ng. $\mathrm{dm}^{-3}$ being determined by a number of factors. Various compounds, some of which unstable, easily oxidized upon contact with air, decomposing under heat or extreme $\mathrm{pH}$ values are involved in the aromatic profile of wine (Ortega-Heras et al., 2002). Higher alcohols and esters are the main contributors to the overall volatile composition of the red wines, which made up to $17-76 \%$ and $16-23 \%$ of the total volatiles, respectively (Manolache $\boldsymbol{e t}$ al., 2018). The esters take a significant share among the volatile aromatic components of wine. The aromatic characteristics of grapes of different varieties vary considerably and have a dominant role in shaping the specific wine aroma as the esterification process begins already in the maturing period (Carey $\boldsymbol{e t}$ al., 2003).

In the wine-making process the microorganisms also change wine composition due to their metabolism. During the alcoholic and malolactic fermentation, under the impact of the medium factors, a large number of volatile aromatic components (esters, higher alcohols and terpenes) have been synthesized (Mendes et al., 2017; Lengyel and Panaitescu, 2017). The greatest numbers of esters are formed during the alcoholic fermentation and wine storage. Their amount depends on the must composition, the fermentation conditions, the yeast strain, aging in contact with oak wood, etc. (Soles et al., 1982; Mateo et al., 1992; Pereira and Pinto, 1998; Camara et al., 1998; Pisarnitskii A., 2001; Stoyanov et al., 2009; Antalick et al., 2015).

Yeasts differ in their capacity to form esters. The apiculate species Hanseniaspora and Saccharomycodes ludwigii have the strongest estrogenic capacity, while Pichia and Torulaspora - the weakest. The yeasts of the genus Saccharomyces differ in their ester producing capacity. In total, Saccharomyces cerevisiae produce significantly more esters compared to Saccharomyces cerevisiae uvarum and Saccharomyces bayanus due to their better alcoholforming capacity (Pereira and Pinto, 1998).

Most of the esters are pleasantly smelling, having a positive influence on wine aroma. In greatest ratios are formed: ethyl acetate, isoamyl acetate (apple aroma, banana), ethyl hexanoate (banana flavor, pineapple, red apple, strawberry, rum), ethyl octanoate (pear aroma, pineapple, apricot, sweets) and ethyl lactate (Ribéreau-Gayon, 2006; http://www.thegoodscentscompany.com). Ethyl acetate predominates quantitatively in wine, which, in a concentration above 100 mg.dm ${ }^{-3}$, gives an oxidized nuance. The content of other agents depends on the yeast strain and the fermentation conditions. As a result significant differences in the amount of isoamyl acetate are observed ranging from $0.86 \mathrm{mg} . \mathrm{dm}^{-3}$ to 2.94 $\mathrm{mg} \cdot \mathrm{dm}^{-3}$. Saccharomyces cerevisiae yeast produces significantly more isoamyl acetate, in contrast to Saccharomyces cerevisiae fermentati and Saccharomyces bayanus that synthesize a larger amount of ethyl hexanoate. Wines fermented with Saccharomyces cerevisiae, Saccharomyces bayanus and Zygosaccaromyces bailii contain more hexyl acetate. Ethyl octanoate is synthesized at the highest rates by Saccharomyces cerevisiae fermentati, Saccharomyces cerevisiae and Pichia fermentans, while 2-phenylethyl acetate and ethyl decanoate by Saccharomyces bayanus (Soles et al., 1982).

At lower fermentation temperatures $\left(20^{\circ} \mathrm{C}\right)$, a greater number of "fruit" esters (ethyl acetate, isoamyl acetate, isobutyl acetate, etc.) are produced. High boiling esters (ethyl octanoate, 2-phenylacetate, ethyl decanoate, etc.) are synthesized in higher quantities at higher temperatures $\left(30^{\circ} \mathrm{C}\right)$. Significant differences in the capacity of yeast to form ethyl and acetate esters are observed. The reason is in existence and activity of different enzyme systems for their formation in the yeas cell. Ethyl esters are mainly synthesized during the exponential phase of yeast cell development, unlike acetate esters, which reach maximum concentration during the stationary phase. The concentration of esters increases significantly during the must fermentation with a higher sugar content (Miranda-Lopez et al., 1992; Balik et al., 2002; Kolarik et al., 2004; Molina et al., 2007).

In tracking the influence of a group of factors on a particular indicator of wine composition, neural networks can be used to produce results more clearly (Cichoski and Unbehauen, 1994). In this type of modeling, the output signal is obtained by converting the input, by means of a set function - sigmoid hyperbolic tangent, exponential, threshold or linear. Layered neural networks are used, with three layers of nonlinear neurons sufficient to approximate complex non-linear correlation. Neural networks are widely used in the modeling, management and optimization of biotechnological processes (Chen et al., 2006, Nicoletti et al., 2009). Their application in the field of winemaking has so far been a basic modeling and optimization of the alcoholic fermentation stage (Cortez et al., 2009; Sablayrolles, 2009).

The objective of the study was to investigate the influence of the technological factors yeast strain, temperature and inoculum yeast culture quantity on the 
synthesis of esters during the alcoholic fermentation in wines and their importance in the formation of wine organoleptic profile.

\section{MATERIAL AND METHODS}

The experiments were carried out with grapes of Cabernet Sauvignon variety. Each experimental variant was crushed and strained off separately and by uniform distribution of the clusters a uniformity of the raw material was ensured. The alcoholic fermentation occurred under the following conditions:

- fermentation substrate $-4.0 \mathrm{~kg}$ of grape pulp, sulfated with $50 \mathrm{mg} \cdot \mathrm{kg}^{-1} \mathrm{SO}_{2}$,

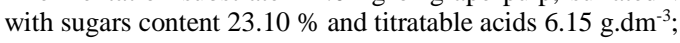

- 48-hour active yeast culture of the strains Saccharomyces cerevisiae Bordeaux and Saccharomyces cerevisiae $8-11$ in quantity of $2 \%, 3 \%, 4 \%$ (the strains were provided by the yeast collection of the Department of Technology of Wine and Brewing, University of Food Technologies, Plovdiv, Bulgaria);

- fermentation temperature $-20^{\circ} \mathrm{C}, 24^{\circ} \mathrm{C}, 28^{\circ} \mathrm{C}$;

The rate of the total esters in the course of the alcoholic fermentation was determined by recording the following steps: onset $\left(1^{\text {st }}\right.$ day), strong fermentation $\left(5^{\text {th }}\right.$ day), silent fermentation $\left(10^{\text {th }}\right.$ day) and after the malolactic fermentation $\left(20^{\text {th }}\right.$ day). Their quantity was identified by the method of saponification with $\mathrm{NaOH}$ (Ivanov et al., 1979).

The experimental results from all variants were modeled through neural networks of the Statistica 8 software package using a second order quasi-newton algorithm describing the influence of time, fermentation temperature and yeast culture on esters synthesis. The number of neurons in the input layer was 3 (temperature, inoculum yeast culture quantity, time) and in the starting layer -1 for each model. The number of neurons in the hidden layer was set to be changed from 3 to 15 . As a result, the network that gave the highest correlation ratio with the experimental data was selected. The results were also presented in the form of surfaces that describe the experimental data with high precision (Chen $\boldsymbol{e t}$ al. 2006, Nicoletti et al., 2009).

After the end of the alcoholic and malolactic fermentation, the wines of al experimental variants were decanted and analyzed by the indicators: alcohol, vol.\% (distillation method, Gibertini distillation apparatus with densitometer); sugar, g.dm ${ }^{-3}$ (Schoorl method); total extract, g.dm ${ }^{-3}$ (Gibertini distillation apparatus with densitometer); sugar-free extract, g. $\mathrm{dm}^{-3}$ (calculation method as difference between the total extract and sugars); titratable acids, g. $\mathrm{dm}^{-3}$ (titration with $\mathrm{NaOH}$ ); volatile acids, g. $\mathrm{dm}^{-3}$ (distillation method followed by titration with $\mathrm{NaOH}$ ); $\mathrm{pH}$ ( $\mathrm{pH}$ meter); total esters, $\mathrm{mg}^{-\mathrm{dm}^{-3}}$ (saponification method with $\mathrm{NaOH}$ ) (Ivanov et al., 1979). The organoleptic characteristics of the wine were evaluated by a 100-score system (a 5-member tasting committee) and by the method of the main characteristics (Tsvetanov, 2001; Prodanova, 2008). The tasting scores of Cabernet Sauvignon experimental wines were illustrated also by means of threelayer neural networks.

Gas chromatographic analysis (GC) was performed of the experimental variant where the content of methyl acetate, ethyl acetate, propyl acetate, isobutyl acetate, butyl acetate, isoamyl acetate, amyl acetate, ethyl hexanoate, ethyl octanoate, ethyl decanoate was identified and qualitatively determined. The analyzes were made with GC 8000 Top Series, CE Instruments with flame ionization detector; helium carrier gas $(50 \mathrm{kPa})$; capillary column fused silica Omegawax $250(30 \mathrm{~m} \times 0.25 \mathrm{~mm}$; ft $0.25 \mu \mathrm{m})$; column temperature program: $25^{\circ} \mathrm{C}(5 \mathrm{~min}), 4^{\circ} \mathrm{C} / \mathrm{min}$ to $210^{\circ} \mathrm{C}(10 \mathrm{~min})$; injector temperature $250^{\circ} \mathrm{C}$; detector temperature $250^{\circ} \mathrm{C}$. The volatile components were extracted from the wine by the "headspace" method (Hrivňak et al., 2004; Kružlicova et al., 2006). Based on the peak area, the ratio difference in the component content between the different variants was calculated. The samples, obtained at $20^{\circ} \mathrm{C}$ and $2 \%$ inoculum yeast culture, were assumed to be the standard (100\%). For comparing both strains, Saccharomyces cerevisiae Bordeaux strain was taken as standard $(100 \%)$.

\section{RESULTS AND DISCUSSION}

When investigating the impact of the studied technological factors on the duration of the alcoholic fermentation it was found that Saccharomyces cerevisiae Bordeaux and Saccharomyces cerevisiae 8-11 strains showed high fermentation activity. By increasing the temperature and the inoculum amount of yeast culture within one temperature range, the process began and ended earlier. To clarify the correlation between the studied fermentation indicators and their impact on wine organoleptic profile, the variation in the total esters ratio was monitored for all experimental variants. Neural networks were generated describing the impact of time, temperature and the inoculum yeast culture quantity on their producing. The results revealed that the influence of the inoculum amount of the studied strains was similar and relatively weaker. The effect of temperature, as an indicator of the fermentation process, on the yeasts ester producing capacity was stronger. Both strains produced more esters at $20^{\circ} \mathrm{C}$ and $24^{\circ} \mathrm{C}$ compared to $28^{\circ} \mathrm{C}$. As the esters production during the alcoholic fermentation occurred by biological way, that was due to the better esterase activity at lower temperatures. In the variants that fermented with a higher ratio of inoculum yeast culture, the content of the metabolite was higher due to the greater number of propagating cells with active esterase.
The results, modeled by the generated neural networks, confirmed the established trend. The esters tended to increase with decreasing temperature, raising the inoculum amount of the yeast culture and the fermentation time. Their higher ratio in the middle of the process was also due to the increasing amount of formed alcohols. The illustrated surfaces (Fig. 1) described their contents in the experimental variants during the fast fermentation. The maximum was recorded

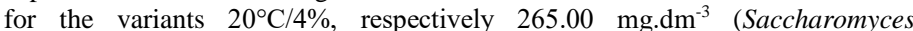

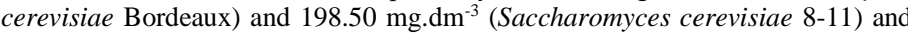

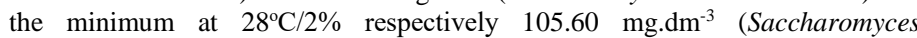
cerevisiae Bordeaux) and $103.00 \mathrm{mg} \cdot \mathrm{dm}^{-3}$ (Saccharomyces cerevisiae 8-11).

Temperature, ${ }^{0} \mathrm{C}$, Inoculum, $\%$, Esters, mg/l

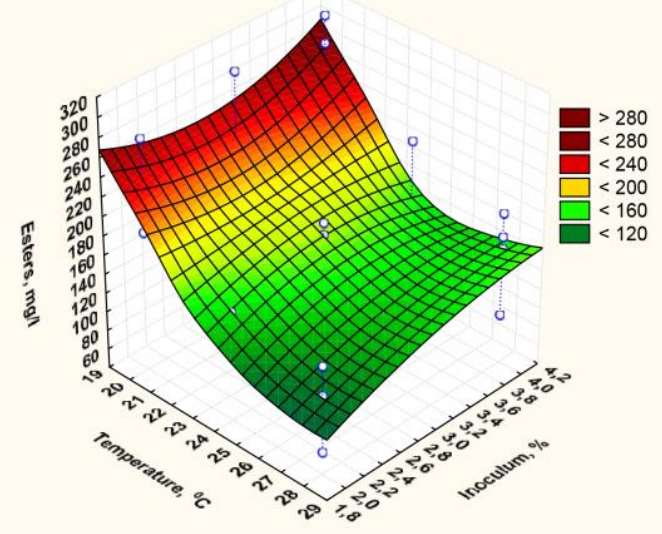

A) strain Saccharomyces cerevisiae Bordeaux Temperature, ${ }^{0} \mathrm{C}$, Inoculum, \%, Esters, mg/l

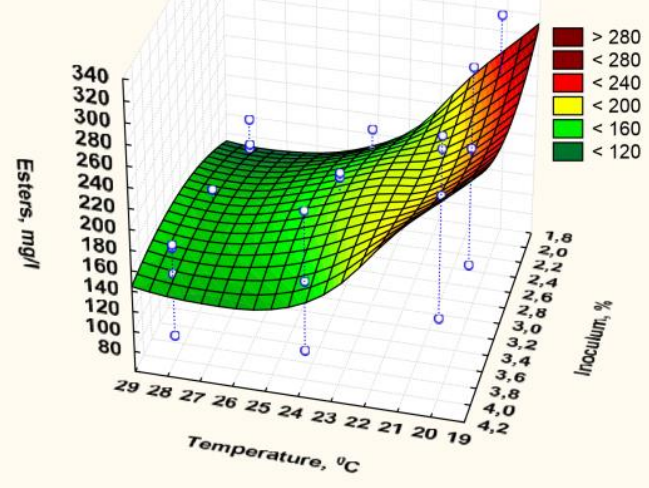

B) strain Saccharomyces cerevisiae 8-11

Figure 1 Changes in the esters concentration during the alcoholic fermentation of Cabernet Sauvignon grape pulp

The chemical composition of the experimental wines with respect to the main indicators and the content of common esters are presented in Table 1.

The better fermentation activity of Saccharomyces cerevisiae 8-11 had determined the lower amount of residual sugars in its variants. The differences in the alcohol content of the samples from both strains were insignificant. The young Cabernet Sauvignon wines were highly extractable, with a thick taste, due to the amount of sugar-free extract. That was related both to the peculiarities of the grape variety, the yeast metabolism and the fermentation conditions. The samples obtained with Saccharomyces cerevisiae 8-11 strain had a higher amoun of sugar-free extract compared to those of Saccharomyces cerevisiae Bordeaux strain. This was also revealed by their organoleptic properties. The wines had better taste and got higher tasting ratings (Fig. 5, 6). The titratable and volatile acidity rates in the variants of both strains were close and were within the normal range for young red wines.

The results in Table 1 showed the better ester producing capacity of Saccharomyces cerevisiae Bordeaux at lower temperatures. The strain synthesized $11.5 \%$ more total esters, compared to Saccharomyces cerevisiae 811. Their quantity had a beneficial effect on the wine aroma, however not always the higher ratio in the variants was associated with a higher tasting score (Fig. 5, 
6). The reason was the correlation between the individual agents or the increased rate of ethyl acetate.

Table 1 Chemical composition and tasting score of Cabernet Sauvignon wines

\begin{tabular}{|c|c|c|c|c|c|c|c|c|c|}
\hline \multirow[b]{2}{*}{ Indicators } & $20^{\circ} \mathrm{C} / 2 \%$ & $20^{\circ} \mathrm{C} / 3 \%$ & $20^{\circ} \mathrm{C} / 4 \%$ & $24^{\circ} \mathrm{C} / 2 \%$ & $24^{\circ} \mathrm{C} / 3 \%$ & $24^{\circ} \mathrm{C} / 4 \%$ & $28^{\circ} \mathrm{C} / 2 \%$ & $28^{\circ} \mathrm{C} / 3 \%$ & $28^{\circ} \mathrm{C} / 4 \%$ \\
\hline & \multicolumn{9}{|c|}{ strain Saccharomyces cerevisiae Bordeaux } \\
\hline Alcohol, vol. \% & 12.75 & 12.95 & 12.72 & 12.84 & 12.72 & 12.81 & 12.74 & 12.76 & 12.80 \\
\hline Sugar, g.dm ${ }^{-3}$ & 2.35 & 1.81 & 2.18 & 1.98 & 2.01 & 2.22 & 2.18 & 2.35 & 2.08 \\
\hline Sugar-free extract, g.dm ${ }^{-3}$ & 26.65 & 27.59 & 27.22 & 26.22 & 27.49 & 26.78 & 26.32 & 27.15 & 26.52 \\
\hline Titratable acids, g.dm ${ }^{-3}$ & 5.70 & 5.58 & 5.65 & 5.78 & 5.50 & 5.50 & 5.35 & 5.70 & 5.58 \\
\hline Volatile acids, g.dm ${ }^{-3}$ & 0.45 & 0.39 & 0.33 & 0.45 & 0.36 & 0.36 & 0.49 & 0.54 & 0.48 \\
\hline $\mathrm{pH}$ & 3.24 & 3.16 & 3.19 & 3.17 & 3.16 & 3.16 & 3.15 & 3.12 & 3.15 \\
\hline Total esters, $\mathrm{mg} \cdot \mathrm{dm}^{-3}$ & 281.60 & 304.00 & 318.00 & 186.00 & 193.60 & 211.20 & 140.80 & 158.40 & 176.00 \\
\hline \multirow[t]{2}{*}{ Tasting score } & 82.62 & 80.37 & 83.37 & 82.75 & 87.12 & 78.87 & 79.62 & 81.37 & 86.75 \\
\hline & \multicolumn{9}{|c|}{ strain Saccharomyces cerevisiae 8-11 } \\
\hline Alcohol, vol. \% & 12.74 & 12.79 & 12.80 & 12.72 & 12.74 & 12.87 & 12.78 & 12.83 & 12.87 \\
\hline Sugar, g.dm ${ }^{-3}$ & 1.74 & 2.01 & 1.48 & 1.48 & 1.10 & 1.04 & 1.67 & 1.00 & 1.17 \\
\hline Sugar-free extract, g.dm ${ }^{-3}$ & 26.26 & 26.79 & 27.52 & 27.72 & 28.10 & 28.16 & 27.13 & 28.20 & 28.33 \\
\hline Titratable acids, g.dm ${ }^{-3}$ & 6.05 & 5.53 & 5.60 & 5.38 & 5.83 & 5.43 & 5.53 & 6.05 & 5.20 \\
\hline Volatile acids, g.dm ${ }^{-3}$ & 0.21 & 0.33 & 0.39 & 0.36 & 0.33 & 0.30 & 0.42 & 0.39 & 0.36 \\
\hline $\mathrm{pH}$ & 3.20 & 3.15 & 3.21 & 3.18 & 3.20 & 3.21 & 3.17 & 3.18 & 3.16 \\
\hline Total esters, $\mathrm{mg} \cdot \mathrm{dm}^{-3}$ & 193.60 & 246.40 & 281.40 & 186.00 & 193.60 & 228.80 & 176.00 & 176.00 & 193.60 \\
\hline Tasting score & 83.44 & 83.22 & 83.33 & 87.44 & 83.89 & 85.44 & 82.11 & 86.78 & 84.00 \\
\hline
\end{tabular}

The trends found were also confirmed by the gas chromatographic analysis of the experimental samples (Fig. 4).

At the highest ratio, Saccharomyces cerevisiae Bordeaux strain synthesized ethyl acetate, followed by isoamyl acetate and ethyl hexanoate. For some agents, the maximum in synthesis was noted at $24^{\circ} \mathrm{C}$, where the amount of propyl acetate and isobutyl acetate was by $11.0 \%$ and $16.0 \%$ higher than the standard $\left(20^{\circ} \mathrm{C} / 2 \%\right)$ respectively. The ratio of the rest identified esters was the highest at $20^{\circ} \mathrm{C}$ and decreased as the temperature went up (Fig. 2).

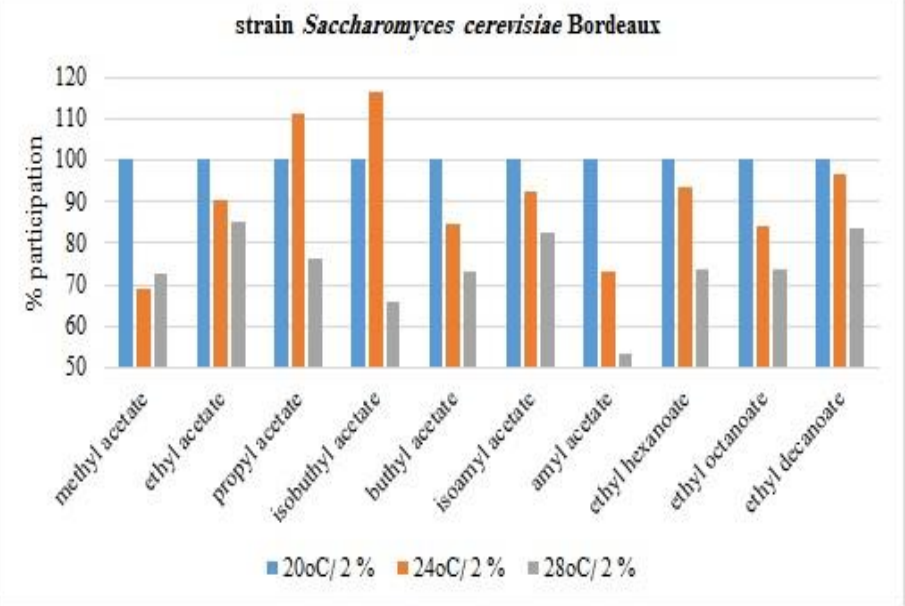

strain Saccharomyces cererisiae 8-11

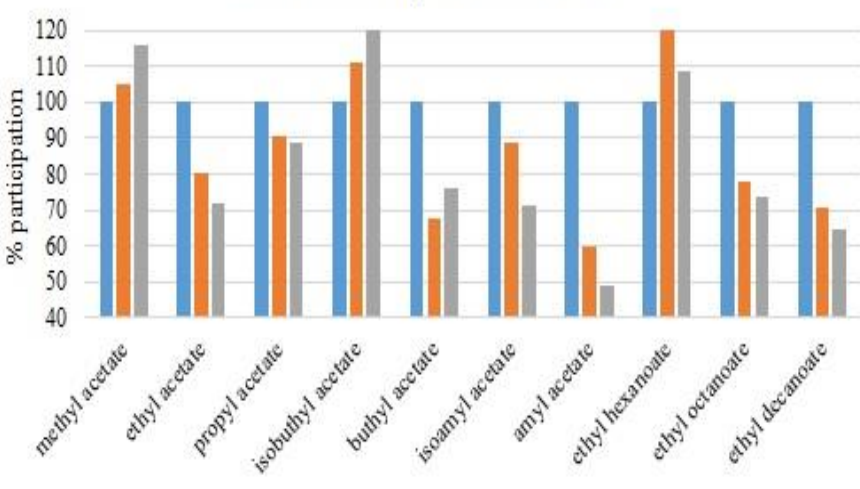

$=200 \mathrm{C} / 2 \%-240 \mathrm{C} / 2 \%-280 \mathrm{C} / 2 \%$

Figure 2 Participation (\%) of the identified esters in Cabernet Sauvignon wines, fermented with Saccharomyces cerevisiae Bordeaux and Saccharomyces cerevisiae 8-11 strains

Esters synthesized from the strain Saccharomyces cerevisiae 8-11 predominantly included ethyl acetate and isoamyl acetate. The quantity of some of the identified representatives, however, marked a maximum at a higher temperature. At $24^{\circ} \mathrm{C}$ more ethyl hexanoate by $13 \%$ was produced while at $28^{\circ} \mathrm{C}-$ by $4.8 \%$ more methyl acetate and $13.8 \%$ more isobutyl acetate. The ratio of the rest esters decreased with increasing the fermentation temperature (Fig. 2).

The weaker ester producing capacity of Saccharomyces cerevisiae 8-11 was also confirmed by the chromatographic analyses. The amount of ethyl acetate, for example, at $20^{\circ} \mathrm{C}$ was by $10.0 \%$, and of isoamyl acetate by $16 \%$ less than those synthesized by Saccharomyces cerevisiae Bordeaux strain under the same conditions (Fig. 3). It was the lower ratios of the fruit esters that explained the lower tasting scores of the variants obtained with Saccharomyces cerevisiae 8-11 strain with respect to the aroma (Fig. 6).

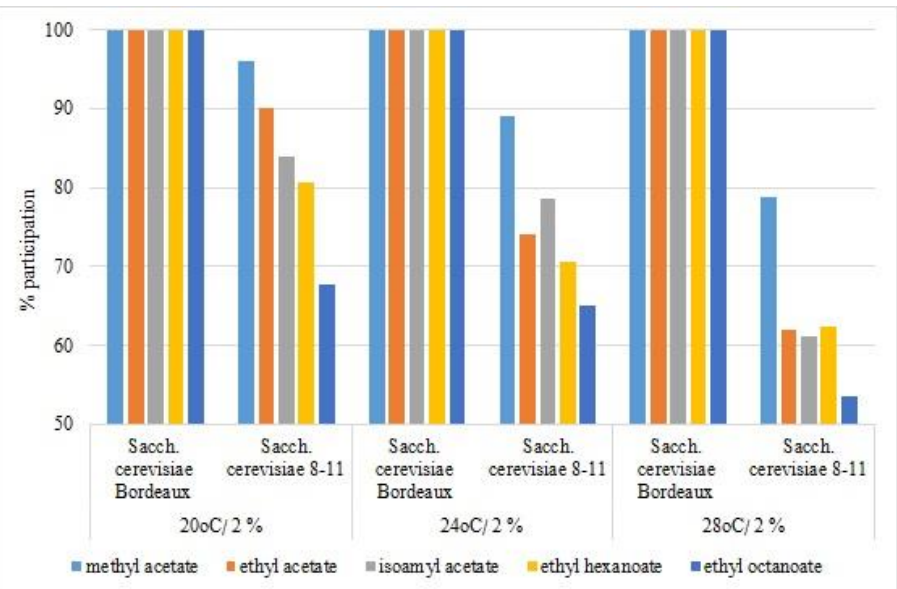

Figure 3 Distribution of esters produced by Saccharomyces cerevisiae Bordeaux and Saccharomyces cerevisiae 8-11 strains in Cabernet Sauvignon wines

Cabernet Sauvignon experimental wines were distinguished for their intense, ruby-red color, fine, harmonious aroma of red fruit, balanced taste with sufficient density, freshness and smoothness (Fig. 5, 6). From the Saccharomyces cerevisiae Bordeaux strain variants the highest tasting score received those fermented at $24^{\circ} \mathrm{C} / 3 \%$ and $28^{\circ} \mathrm{C} / 4 \%$ respectively 87.12 and 86.75 points. From the variants of Saccharomyces cerevisiae 8-11 strain the best organoleptic characteristics were determined for those obtained at $24^{\circ} \mathrm{C} / 2 \%$ and $28^{\circ} \mathrm{C} / 3 \%$ and rated respectively with 87.44 and 86.78 points (Table 1 ).

The results of the mathematical modeling for the impact of the fermentation process indicators on the organoleptic profile and the chemical components of the wines confirmed the obtained tasting ratings. The best characteristics had the variants with lower ester content. The stronger influence of temperature on the fermentation process and the wine components was more pronounced at Saccharomyces cerevisiae 8-11 strain than at Saccharomyces cerevisiae Bordeaux strain. 


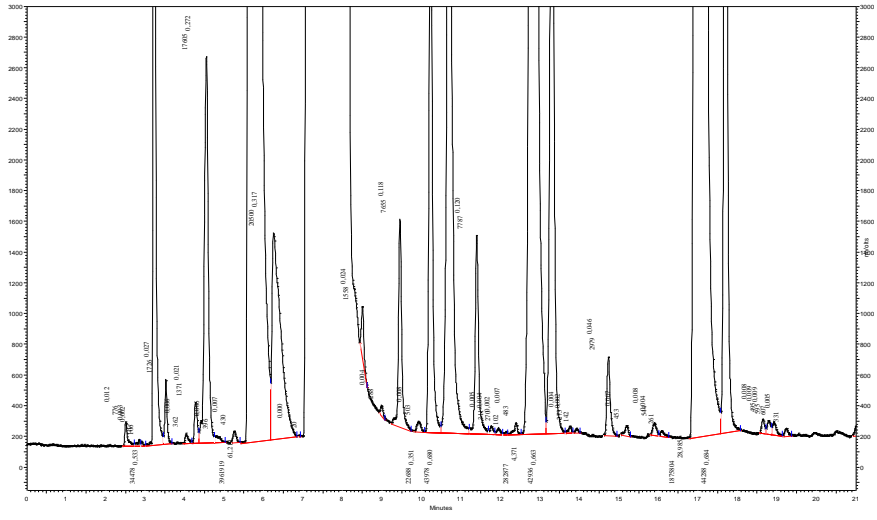

$0-20 \min$

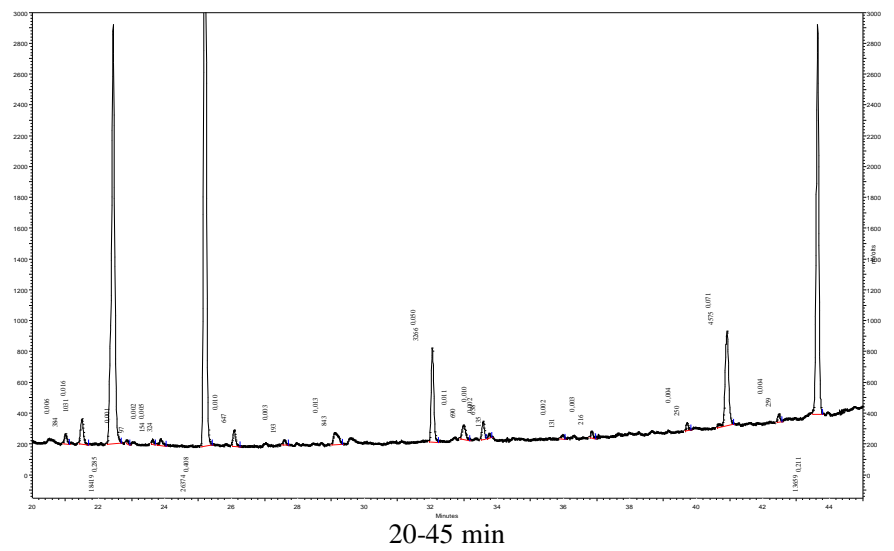

A, strain Saccharomyces cerevisiae Bordeaux
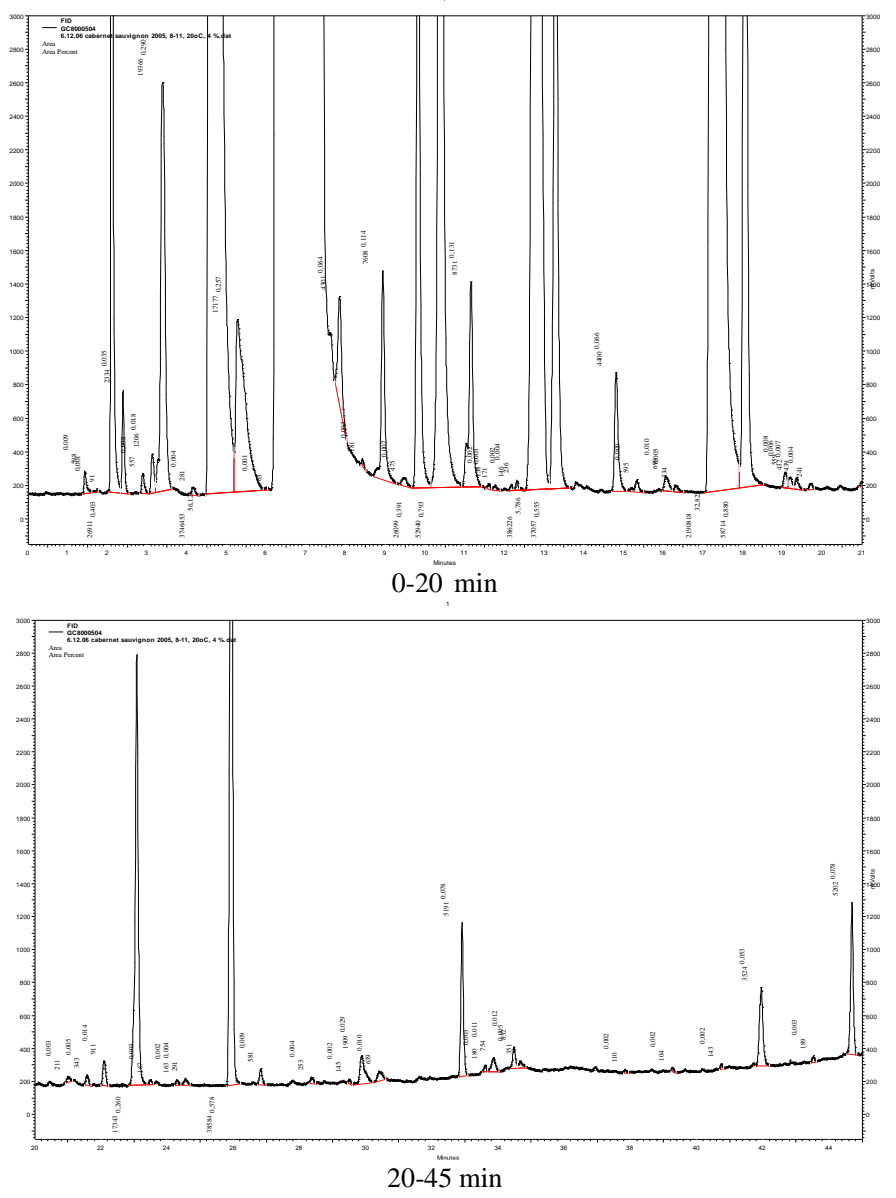

B, strain Saccharomyces cerevisiae 8-11

Figure 4 Chromatographic profile of Cabernet Sauvignon wine, obtained at $20^{\circ} \mathrm{C} / 4 \%$ with Saccharomyces cerevisiae Bordeaux and Saccharomyces cerevisiae 8-11 strains
Fig. 5 showed the tasting scores of Cabernet Sauvignon experimental wines by means of three-layer neural networks, with 12 neurons in the hidden layer for Saccharomyces cerevisiae Bordeaux strain and 10 neurons for Saccharomyces cerevisiae 8-11.

\section{MS Residual $=17,647$}

Organoleptic assesment

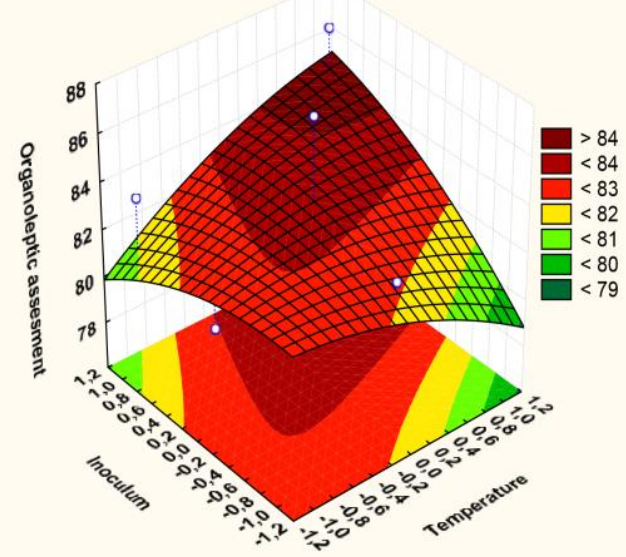

A) strain Saccharomyces cerevisiae Bordeaux

\section{MS Residual $=5,38697$}

Organoleptic assesment

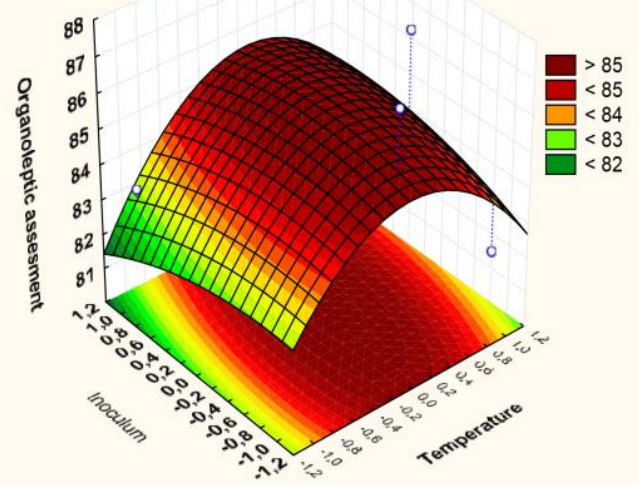

B) strain Saccharomyces cerevisiae 8-11

Figure 5 Response surfaces for describing the tasting scores of Cabernet Sauvignon wines

The presented models of the organoleptic analysis results revealed that Saccharomyces cerevisiae 8-11 strain was more suitable for the production of wine of this variety because the resulting surface had a more pronounced maximum and homogeneity of the tasting scores. The variant, fermented at $28^{\circ} \mathrm{C} / 3 \%$ was characterized by an intense ruby-red color, and dense and balanced taste (Fig. 6). 


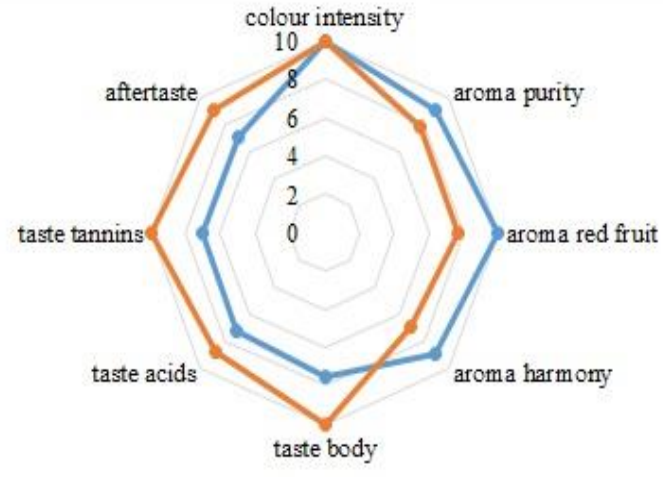

$\longrightarrow$ strain Saccharomyces cerevisiae Bordeaux $(24 \circ \mathrm{C} / 3 \%)$ strain Saccharomyces cer evisiae \&-11 (28oC/3\%)

Figure 6 Organoleptic characteristics of Cabernet Sauvignon wines

\section{CONCLUSION}

When monitoring the impact of the technological factors during fermentation, it was found that the studied yeast strains had different ester producing capacity. The more pronounced influence of the factor temperature compared to the inoculum yeast culture quantity was observed. The strains produced more esters at $20^{\circ} \mathrm{C}$ and $24^{\circ} \mathrm{C}$ than at $28^{\circ} \mathrm{C}$. The strain Saccharomyces cerevisiae Bordeaux exhibited better ester producing capacity and synthesized $11.5 \%$ more total esters, compared to Saccharomyces cerevisiae 8-11. Ethyl acetate and isoamyl acetate were synthesized in the largest amount.

The applied neural networks and the derived mathematical models adequately described the fermentation processes at the combination of grape variety - yeast strain - conditions.

It was found that the impact of esters produced by the yeasts on the organoleptic profile of the wines was not because of their total amount but mainly due to the ratio between the individual representatives.

Under the experiment conditions the strain Saccharomyces cerevisiae 8-11, fermented at $28^{\circ} \mathrm{C}$, with $3 \%$ inoculum yeast culture was identified as more suitable for the production of Cabernet Sauvignon wines.

\section{REFERENCES}

ANTALICK, G., ŠUKLJE, K., BLACKMAN, J. W., MEEKS, C., DELOIRE, A., SCHMIDTKE, L. M. 2015. Influence of grape composition on red wine ester profile: comparison between Cabernet sauvignon and Shiraz cultivars from Australian warm climate. Journal of Agricultural and Food Chemistry, 63 (18), 4664-4672. https://doi.org/10.1021/acs.jafc.5b00966

BALIK, J., GOLIAŠ, J., VEVERKA, J., KYSELAKOVA, M., NEMCOVA, A. ŚUDERLOVA, L., VEJROSTA, J. 2002. Wine volatiles composition in the sensory evaluation of bouquet and flavour of two vine cultivars. Horticultural Science (Prague), 29 (1), 4-11. https://doi.org/10.17221/4463-HORTSCI CAMARA, J., MARQUES, J., ALVES, M., SPRANGER, I. 1998. The influence of the fermentation on the concentration of higher alcohols and esters in young Madeira wines. Proceeding of the XXIII World Congress of Vine and Wine, Lisbon: 367-369.

CAREY, V., BONNARDOT, V., SCHMIDT, A., THERON, J. 2003. The interaction between vintage, vineyard site (mesoclimate) and wine aroma of Vitis vinifera L. cvs. Sauvignon blanc, Chardonnay and Cabernet Sauvignon in the Stellenbosch-Klein Drakenstein wine producing area, South Africa (1996-2000). Bulletin de l'O.I.V., 76-863-864 (Janvier-Fevrier), 4-26.

CHEN, L. Z., NGUANG, S. K., CHEN, X. D. 2006. Modelling and optimization of biotechnological processes. Artificial Intelligence Approaches. Berlin: Springer, 15, 123 p., ISBN 978-3-540-32493-5. https://doi.org/10.1007/978-3540-32493-5

CICHOSKI, A., UNBEHAUEN, R. 1994. Neural networks for optimization and signal processing. International Journal of Adaptive Control and Signal Processing, 8 (3), 299-300. https://doi.org/10.1002/acs.4480080309

CORTEZ, P., CERDERIA, A., ALMEIDA, F., MATOS, T., REIS J. 2009 Modeling wine preferences by data mining from physicochemical properties

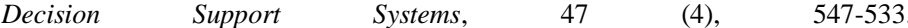
https://doi.org/10.1016/j.dss.2009.05.016

HRIVŇAK, J., REPKA, V., FRIČOVA, J. 2004. Characterisation of wine aroma by sorption and desorption of the gas phase. Book of Abstracts of the XXVIII World Congress of Vine and Wine, Wien: 125.

IVANOV, T., GEROV, S., YANKOV, A., BAMBALOV, G., TONCHEV, T. NACHKOV, D., MARINOV, M. 1979. Practicum in wine technology. Plovdiv: Publ. House Hristo G. Danov, 530 p. (BG)

KOLARIK, M., HATRIKOVA, Z., HRIVŇAK, J., MACKOVA, M. 2004. Pure yeast culture and their influence on quality and aroma of wine. Vinohrad, 42 (6), 5-6. (SK)
KRUŽLICOVA, D., MOCAK, J., HRIVŇAK, J., ĎURČEKOVA, T., ARGAY, M. 2006. Classification of Slovak varietal wines by capillary GC with solidphase microextraction. Zbornik vedeckych prac, XVI medzinarodna konferencia Chromatograficke metody a zdravie človeka, Pieštany: ÚACH FCHPT STU, Bratislava, pp. L17_1-L17_5, 2006.

LENGYEL, E., PANAITESCU, M. 2017. The management of selected yeast strains in quantifying terpene flavours in wine. Management of Sustainable Development, Sibiu, Romania, 9 (1), 27-30. https://doi.org/10.1515/msd-2017$\underline{0010}$

MANOLACHE, M., POP, T. I., BABES, A. C., FARCAS, I. A., GODOROJA, M., CĂLUGĂR, A., GAL, E. 2018. Assessment of volatile compounds of some red wine samples from Republic of Moldova and Romania using GC-MS analysis. Agriculture, 1-2 (105-106), 40-47.

MATEO, J., JIMENEZ, M., HUERTA, T., PASTOR, A. 1992. Comparison of volatiles produced by four Saccharomyces cerevisiae strains isolated from Monastrell musts. American Journal of Enology and Viticulture, 43 (2), 206-209. MENDES, I., SANCHEZ, I., FRANCO-DUARTE, R., CAMARASA, C., SCHULLER, D., DEQUIN, S., SOUSA, M. J. 2017. Integrating transcriptomics and metabolomics for the analysis of the aroma profiles of Saccharomyces cerevisiae strains from different origin. BMC Genomics, 18, 455-464. https://doi.org/10.1186/s12864-017-3816-1

MIRANDA-LOPEZ, R., LIBBEY, L., WATSON, B., McDANIEL, M. 1992

Identification of additional odor-active compounds in Pinot noir wines. American Journal of Enology and Viticulture, 43 (1), 90-92.

MOLINA, A., SWIEGERS, J., VARELA, C., PRETORIUS, I., AGOSIN, E. 2007. Influence of wine fermentation temperature on the synthesis of yeastderived volatile aroma compounds. Applied Microbiology and Biotechnology, 77 (3), 675-687. https://doi.org/10.1007/s00253-007-1194-3

NICOLETTI, M. C., JAIN, L. C., GIORDANO, R. C. 2009. Computational intelligence techniques for bioprocess modelling, supervision and control. Berlin Springer, 218, 1-23, ISBN 978-3-642-01888-6. https://doi.org/10.1007/978-3642-01888-6

ORTEGA-HERAS, M., GONZALEZ-SANJOSE，M., BELTRAN， S. 2002 Aroma composition of wine studied by different extraction methods. Analytica Chimica Acta, 458, 85-93. https://doi.org/10.1016/S0003-2670(01)01526-4

PEREIRA, O., PINTO, J. 1998. Role of the yeast strain in the aromatic components and white "Vinho Verde" quality. Proceeding of the XXIII World Congress of Vine and Wine, Lisbon: 503-509.

PISARNITSKII, A. 2001. Formation of wine aroma: tones and imperfections caused by minor components (review). Applied Biochemistry and Microbiology, 37 (6), 552-560. https://doi.org/10.1023/A:1012390731145

RIBEREAU-GAYON, P., GLORIES, Y., MAUJEAN, A., DUBOURDIEU, D

2006. The chemistry of wine stabilization and treatments. Handbook of Enology, 2 (part I, chap. 7), John Wiley\&Sons, Ltd: 205-231, ISBN 0-470-01037-1.

PRODANOVA, N. 2008. Tasting or how to get to know the wine. Sofia: Gourmet, 105-118, ISBN: 9789542917205.

SABLAYROLLES, J. M. 2009. Control of alcoholic fermentation in winemaking: Current situation and prospect. Food Research International, 42 (4), 418-424. http://dx.doi.org/10.1016/j.foodres.2008.12.016

SOLES, R., OUGH, C., KUNKEE, R. 1982. Ester concentration differences in wine fermented by various species and strains of yeasts. American Journal of Enology and Viticulture, 33 (2), 94-97.

STOYANOV, N., BLAGOEVA, N., MITEV, P., SPASOV, H. 2009. Study of the influence of oak wood of winter oak $(Q$. sessilis; $Q$. Petraea) on the organoleptic characteristic of red wines. Lozarstvo i vinarstvo, 6, 13-19. (BG) TSVETANOV, O. 2001. How to Taste Wine. Sofia: Gourmet, 43-46. (BG) http://www.thegoodscentscompany.com 